\title{
Mobile learning practices and preferences a way forward in enhancing dental education learning experience
}

Jane Manakil, Roy George

School of Dentistry and Oral Health, Griffith University, Queensland, Australia

\author{
Address for correspondence: \\ Associate Prof. Roy George, \\ School of Dentistry, Unit Head \\ Endodontics, Griffith Health-G40, \\ Griffith University, Gold Coast Campus, \\ Parklands, QLD 4215, Australia. \\ E-mail: drroygeorge@gmail.com
}

\begin{abstract}
Objective: To explore undergraduate dental students' mobile technological preferences and their use in learning and patient management in dentistry. Materials and Methods: An online survey questionnaire (62 Questions in five parts) was designed to investigate the impact of mobile technology in dental education amongst the Bachelor in Dental Science and Graduate Dental Science ( $1^{\text {st }}-5^{\text {th }}$ year) students, at the School of Dentistry, Griffith University, Australia. Participation was voluntary. Results: In total, 251 dental students consented to participate in the study. The majority of participants were in the age group of 18-25 (65.3\%). Mobile devices were used by $93.2 \%$ of the respondents for various activities including for educational purposes. Laptops and smartphones' ownership was almost similar; however, $75.7 \%$ favoured laptop as the primary device for resource storage, study, research, and organization of study materials. Social media were used by $52 \%$ of the 5 th year respondents for studies and course-related activities. Majority of the students $(78.8 \%)$ indicated that mobile devices with their software applications could positively assist in patient education and management; however, the relative lack of user-friendly quality applications meant that only $15 \%-25 \%$ of students used software applications for these purposes. Conclusion: The large student ownership of mobile devices and increased interest in its use to enhance learning experiences should encourage universities and software developers to funding research into mobile learning.
\end{abstract}

Key words

Dental education, mobile learning, mobile technology, smart mobile devices

\section{INTRODUCTION}

Mobile technology is playing an increasingly significant role in the field of education: However, it is questionable if excellence in education could be achieved with technological inequity. ${ }^{[1,2]}$ Mobile learning (M-learning) allows students to gain access to information anywhere and at anytime. ${ }^{[3]}$ Enhancing learners' satisfaction, encouraging learners' autonomy, empowering system functions, and enriching interaction and communication activities have a significant influence on the acceptance of M-learning systems. ${ }^{[4]}$ Despite the possible benefits of technology, Kirkwood and Price suggested that the

\begin{tabular}{|l|l|}
\hline \multicolumn{2}{|c|}{ Access this article online } \\
\hline Quick Response Code: & Website: \\
\hline & www.ejgd.org \\
\cline { 2 - 3 } & \\
\hline & DOI: \\
\hline
\end{tabular}

benefits of technology in higher education are ambiguous and contested, with little consensus on their impact on learning and teaching in higher education. ${ }^{[5]}$ Although mobile technology can motivate students, their learning achievement may still be unsatisfactory due to the ambiguity of the learning resources or accessibility. ${ }^{[6]}$ It is thus important clearly discern the role and usage of mobile technology in learning and teaching. ${ }^{[7]}$

Currently, there are numerous companies offering mobile devices. however, the core to these technologies is the operating systems and applications that can

This is an open access article distributed under the terms of the Creative Commons Attribution-NonCommercial-ShareAlike 3.0 License, which allows others to remix, tweak, and build upon the work non-commercially, as long as the author is credited and the new creations are licensed under the identical terms.

For reprints contact: reprints@medknow.com

How to cite this article: Manakil J, George R. Mobile learning practices and preferences a way forward in enhancing dental education learning experience. Eur J Gen Dent 2017;6:22-8. 
enhance its usability. Playing an equally important role in the increasing popularity of mobile devices is the development of reliable platform to transfer data at a substantially rapid rate. ${ }^{[8]}$ The primary problem in the technological pedagogical knowledge application is lack of understanding of technology use and its relevance in the field of education. ${ }^{[7]}$ Hence, the pedagogical content knowledge frameworks of the technology should explore concepts and improved methods that can enhance learner's skills though the incorporation of technology in learning. ${ }^{[9]}$

Dental education requires development of professional knowledge, patient management, and operative skills in providing holistic patient care. Mobile technologies, with its range of hardware and software applications, are increasingly being made available to assist students in many aspects of the professional education. The future of any professional education may revolve around mobile devices and software applications that not only assist in learning but also help optimize and manage one's life as a health-care provider.

There is currently limited knowledge of the use of mobile technology by undergraduate dental students for the purpose of professional learning. It was indicated that for universities to adopt mobile technology successfully it is essential and extremely important to understand student's access to technology and use. ${ }^{[10]}$ The present study explores undergraduate dental student's technological preferences and their use in learning and patient management.

\section{MATERIALS AND METHODS}

The Human Ethics Committee, Griffith University, approved this research protocol before commencement of the study. The questionnaire was designed to investigate the impact of mobile technology in dental educational experience and patient interaction, among the cohorts from Bachelor in Dental Science and Graduate Dental Science $\left(1^{\text {st }}-5^{\text {th }}\right.$ year$)$ program, at the School of Dentistry, Griffith University, Australia.

The online survey questionnaires were developed using a modified version of Lime Survey ${ }^{\mathbb{R}}$ production environment (Version V1.9X). The survey was made available to all students for 12 months (starting August 2013). All cohorts' of the dental science program from the School of Dentistry were invited to participate in the survey. Students were e-mailed with an online link to take part in this one-off nonobligatory anonymous survey, using their university login username and password.

The questionnaire included five parts with a total of 62 questions on student awareness and application of mobile technology in education. The first part of the questionnaire looked at personal information. The second part of the study looked at the most common devices used to access learning resources or for communication. This part of the study evaluated student's preference for devices that assist or enhance learning (mobile smartphone, tablet device, notebooks, or other devices). This part further looked at preferred operating systems, evaluated the technical comprehension and application of the device for study purposes over the length of the dental educational program. The third part of the questionnaire focused on the awareness of online learning resources such as blackboard and lecture capture.

The fourth part of the study assessed the student's propensity to use social networking as an adjunct to facilitate learning. The students were encouraged to report their preferences and frequency of usage of various common social and professional networking sites. The frequencies were measured on a 5-point Likert scale of $1-5(1=$ always to $5=$ never $)$. This part of the study also looked at the student perceptions of professional networking site for profile building, career opportunities, and as a platform for discussions and exchange of knowledge.

The fifth part of the questionnaire was only inclusive for students providing direct patient care $\left(3-5^{\text {th }}\right.$-year clinical students). This section included open-ended comments on methods to improve M-learning experience and development of technology in dental practice management.

The completed questionnaires were entered into a spreadsheet and the responses to items within all domains were tabulated as frequency distributions. The answer to the open-ended question about the preferred educational experience and suggestions was transcribed, and common themes were identified and grouped as the percentage frequency. Cronbach's alpha was utilized to test internal consistencies within the questionnaire.

\section{RESULTS}

In total, 251 dental students from the Graduate Diploma in Dentistry and Bachelor in Dental Science program, at the School of Dentistry, Griffith University, consented to participate in this confidential survey study. Among the participants, 65.3\% were between 18- and 25-year-old and $56.2 \%$ were female students. Majority of the participants $(80.1 \%)$ were Australian and the rest were international students.

This study showed that ownership of laptops (90.8\%) and smartphones (88.4\%) was almost similar. The ownership of tablet devices by students (47.8\%) was less; however, $12.7 \%$ of students indicated that they would like to own one later. Significantly, nonmobile devices such as 
the traditional desktop computer usage was limited to cohorts (35.1\%) [Table 1]. On the consideration of the preferred operating system for tablets and smartphones, $45.4 \%(n=114)$ favored IOS (Apple Inc., CA, USA) while $35.5 \%(n=89)$ preferred Android OS and a few have indicated different operating systems.

Information on the preferred methods of learning, 93.2\% respondents indicated that they downloaded lectures as PowerPoint presentations and notes for learning. Although about $70.9 \%(n=178)$ visited the blackboard, only $37.5 \%$ cohorts used lecture capture (Lectopia) which can also be downloaded in MP4 format. Downloaded learning materials were mostly stored on laptops/notebooks and the most popular cloud-based service used by students was Dropbox ${ }^{\mathrm{TM}}(35.9 \%)$, the use of other cloud-based software applications was not popular [Table 2]. The examination for the popular media that can enhance learning, $61.8 \%(n=155)$ students considered YouTube, contributed to expanding their knowledge while iTunes were used mainly for entertainment. However, the open comments on the selected Information and Communication Technology (ICT) application showed lecture capture, lecture slides, printing lecture notes, submission of assignments into the blackboard, and interactive learning of anatomy were the measure of technology utilization in the field of education in this study.
On the topic of technological devices, $75.7 \%$ favored laptop as the primary device for resource storage, study, research, and organization of study materials [Table 3]. Very few respondents used smartphones for educational purposes. Laptops were preferred for web browsing, E-mail communications, and professional activities $168.5 \%$, $48.6 \%$, and $76.5 \%$ ), respectively, while $33.9 \%$ students used the smartphones for E-mail communications. Interestingly, smartphones were extremely popular for entertainment, information while traveling and relaxing $(61.4 \%$ and $45.8 \%$, respectively).

The questionnaire on the use of social networking sites, Facebook $^{\circ}(97 \%)$ was the most commonly used social networking site; this was followed by Google chat and Twitter at $21.1 \%$ and $11.6 \%$, respectively. The use of Facebook $^{\odot}$ among the dental cohorts for educational activities showed a response of $72.8 \%$, with the $52 \%$ of the $5^{\text {th }}$ year respondents indicated that they used it for studies and course-related activities. The study did not show any influence of age or sex on the ownership of mobile devices or the use of social networking sites for education.

This study showed that students (16.7\%) were not inclined to use professional networking websites (e.g., LinkedIn, ResearchGate etc.) before graduation; however, they indicated that they would consider using professional websites following graduation. Fifty-six percent of the students acknowledged that professional

\begin{tabular}{lcccc}
\hline \multicolumn{5}{|c}{ Table 1: Current and perceived future ownership of mobile and nonmobile computing devices } \\
$\qquad$ & I own this (\%) & I will buy one soon (\%) & I do not plan to buy (\%) & No responses (\%) \\
\hline Smartphones & 88.4 & 1.2 & 4.0 & 6.4 \\
Tablets & 47.8 & 12.7 & 33.1 & 6.4 \\
Note book/laptop & 90.8 & 0.4 & 2.4 & 6.4 \\
Desktop & 35.1 & 4.0 & 54.6 & 6.4 \\
\hline
\end{tabular}

\begin{tabular}{lccc}
\hline Table 2: Utilization of online learning resources & & & \\
Resources & Always (\%) & Never (\%) & No-responses (\%) \\
\hline Lecture notes, slides/PowerPoint & 93.2 & 0 & 4.4 \\
Lectopia (lecture capture) & 37.5 & 4.2 & 4.8 \\
Blackboard & 70.9 & 31.5 & 5.2 \\
Podcast/video & 14.3 & 8.8 & 5.4 \\
YouTube ${ }^{\circledR}$ & 23.9 & 70.1 & 6.6 \\
itunes ${ }^{\circledR}$ & 7.2 & 49.4 & 42.6 \\
Wimba & 2.4 & 20.7 & 9.9 \\
Cloud (storage of data online, e.g., Dropbox, iCloud, SkyDrive.) & 35.9 & & \\
\hline
\end{tabular}

\begin{tabular}{|c|c|c|c|c|}
\hline Devices & Always (\%) & Occasionally (\%) & Never (\%) & Not applicable (\%) \\
\hline Tablets & 19.9 & 30.7 & $24 \cdot 3$ & 25.1 \\
\hline Smartphones & 6.0 & 43 & 40.2 & 10.8 \\
\hline Note books/laptops & $75 \cdot 7$ & 13.2 & 3.2 & 8 \\
\hline Desktops & 26.3 & 16.4 & 19.9 & 37.5 \\
\hline
\end{tabular}


networking websites were good for enhancing knowledge while $45.5 \%$ students claimed these sites could help them in access career web addresses and $37.2 \%$ felt this can be a tool for connecting them with continuing educational websites [Table 4]. The reliability evaluation of this interrelation showed a high reliability $($ Cronbach's alpha $=0.882)$.

The final part of the survey was designed to assess the use of technology for clinical applications among students in the $3-5^{\text {th }}$-year of the program. Although $78.8 \%$ students indicated that mobile devices with their software applications could positively assist in patient education and management, only $15 \%-25 \%$ of students used software applications for these purposes. The main software applications downloaded on the mobile devices were PubMed Central ${ }^{\circledR}, \mathrm{MIMS}^{\odot}$, and drug index [Table 5].

\section{DISCUSSION}

Learning is a deeply personal experience that can be enhanced by greater learner interactivity: Promoting learner's efficiency, motivation, cognitive effectiveness, and flexibility of learning style. ${ }^{[1]} \mathrm{M}$-learning is revolutionizing the way learning resources are accessed; in essence, providing new and enhanced learning experiences. The present study explores role of mobile technology in dental education and career building. Despite this study only looking at the M-learning

\begin{tabular}{|c|c|c|c|}
\hline & Yes (\%) & Uncertain (\%) & No $(\%)$ \\
\hline $\begin{array}{l}\text { Make my CV and profile } \\
\text { visible to professional } \\
\text { recruiters }\end{array}$ & 47.2 & 8.7 & 44.2 \\
\hline $\begin{array}{l}\text { Discuss selected topics } \\
\text { with peers or colleagues }\end{array}$ & 58.0 & 5.2 & 36.8 \\
\hline $\begin{array}{l}\text { Provides an opportunity } \\
\text { to attend online forum } \\
\text { and discussions }\end{array}$ & 56.7 & 6.5 & 36.8 \\
\hline Establishes your brand & 40.3 & 7.4 & 52.4 \\
\hline $\begin{array}{l}\text { Enhances your } \\
\text { professional network }\end{array}$ & 37.2 & 20.3 & 42.4 \\
\hline $\begin{array}{l}\text { Provide an opportunity } \\
\text { for career advancement }\end{array}$ & $45 \cdot 5$ & 6.9 & 47.6 \\
\hline
\end{tabular}

preference of a localized demographic region, it should be noted that worldwide access to mobile technology is significant, encouraging.

Technological content knowledge is important for academics to plan new teaching methods. ${ }^{[9]}$ Factors that determine success of M-learning include: performance expectancy, effort expectancy, social influence (SI), perceived playfulness, and self-management of learning. These factors may be further modified by age and gender. ${ }^{[12,13]}$ It has been reported that "self-management in learning" is often associated with older people while "effort performance" and "Sis" are more often associated with younger age groups. ${ }^{[12,13]}$ The present study did not show any disparity among different age groups or sex in terms of ownership of mobile device or usage for education and social networking.

The functionality and use of mobile technologies essentially depend on the software and the software applications that are available for the device, and the awareness the learners and educators have of how to use this for M-learning. ${ }^{[14]}$ In the present study, the ownership of smartphones (88.4\%) and laptops (90.8\%) was quite similar; interestingly, it was also noted that the preference for the operating system (IOS vs. Android OS) differed by only $9.9 \%$. Students $(75.7 \%)$ indicated they preferred laptops/notebooks to the smartphones and tablets devices to organize their learning material. The student's preference for the operating systems and devices may be based on their experience of the applications and individual device performance. ${ }^{[15]}$ It is, hence, important that universities' design software applications or systems that deliver teaching material efficiently across a number of different operating platforms.

The broader potential of mobile technology in learning and teaching is the freedom of location, time flexibility, and the ability to easily initiate group-based learning. ${ }^{[6]}$ Martin and Ertzberger $\mathrm{J}$ reported that student attitude to M-learning content delivery through tablets and phones was highly positive; however, students' academic achievements were much higher when contents were accessed using traditional laptops or desktop computers. ${ }^{[17]}$ The present study showed that tablets and smartphones were used more for social

\begin{tabular}{lcccc}
\hline \multicolumn{2}{l}{ Table 5: Most common purpose for the use of mobile software applications in student dental clinics } \\
& Always (\%) & Sometimes (\%) & Never (\%) & Not applicable (\%) \\
\hline Diagnosis & 15.5 & 31.1 & 6.4 & 47 \\
Treatment planning & 19.1 & 28.7 & 6.4 & 45.8 \\
Patient education & 25.5 & 27.1 & 3.2 & 44.2 \\
Drug dose estimation & 18.3 & 29.9 & 4.4 & 47.4 \\
PubMed & 3.6 & 17.9 & 26.3 & 52.2 \\
MIMS & 5.2 & 15.9 & 27.9 & 51 \\
Drug index & 1.2 & 12.7 & 29.9 & 56.2 \\
\hline
\end{tabular}


interaction, relaxation rather than as a learning tool by students $(45.8 \%$ and $61.4 \%$, respectively). However, laptops/notebooks were preferred for educational web browsing and professional activities $(68.5 \%$ and $76.5 \%$, respectively) in comparison to smart devices. Alexander has elaborated on a nomadic existence of students in mobile computing world creating a subspace where hardware becomes the platform for the academic world to conduct collaborative learning anywhere anytime. ${ }^{[18]}$ It should be acknowledged that the rapid changes in mobile hardware and software technology might make smartphones and tablets futuristic tools for learning and teaching.

The E-learning-management systems that are applied widely in professional educational systems these days are variants of WebCT ${ }^{\circledR}$ which evolved into the Blackboard $^{\circledR} \cdot{ }^{[19,20]}$ In the present study, $70.9 \%$ students used blackboard for accessing course materials. Lecture notes as PowerPoint ranked as the top downloads (93.2\%) from the blackboard. This study highlighted the continuing dependence on traditional teaching (lecture notes and PowerPoint) to enhance learning; however, unlike traditional methods of keeping physical copies, digital lecture downloads allowed for organization of material on digital mobile devices. Cloud-based storage of educational resources provides an innovative method to access and share learning materials. Currently, there are a number of companies offering free cloud-based storage that enables mobile users to access and share materials anywhere and anytime. Our study showed that only a small number of students (35.9\%) currently use cloud-based storage (e.g., Dropbox ${ }^{\mathrm{TM}}$ ) to store and share their learning materials. We presume that, with increasing knowledge of mobile technology and cloud-based storage platforms, more students will embrace M-learning. To enhance the effectiveness of E-learning, it is suggested that educators and students be provided with knowledge and skills to overcome the limitations associated with access and use of digital information. ${ }^{[4]}$ Gikas and Grant highlighted the increased usage of mobile computing technology in day-to-day interactive and collaborative education and course content shared by students through Web 2.0 and social media. ${ }^{[3]}$ This was reflected also in an earlier study where the M-learning increased student confidence in learning the course content. ${ }^{[21]}$

Dental and medical communities have embraced social media in its scholarly activities. A North American dental school survey in 2012 showed that $85 \%$ of students used social media, which was similar to that observed among orthopedic residents in another study. ${ }^{[22,23]}$ It was reported that social network websites could be used by students to connect and exchange knowledge with peers, clinicians, lecturers, and professional associations. ${ }^{[24]}$ In this study, 97\% students used Facebook ${ }^{\circ}$, with $72.8 \%$ utilizing this social medium for educational activities. Other professional networking sites such as LinkedIn ${ }^{\circledR}$ and Research Gate $^{\circledR}$ were perceived by $56 \%$ of the students as a source for expansion of knowledge and accessing career opportunity (45\%). Various aspects of professional networking were queried (career development, peer studies, advances in knowledge, increasing efficiency in work practices, people skills) and reliability of the test questions proved very strong. It has been reported that an increase in student representation and participation (in dental education) using social or professional network could help develop a collaborative global study environment. ${ }^{[25]}$ Currently, social media offer user the ability of collaborating, creating, and editing information; however, for social media to be useful in enhancing learning experience, it is important for educational providers to understand how people learn and engage in a social space.

In healthcare, the use of information technology can help in patient management. ${ }^{[26]}$ In 2014 , survey by physician's consulting group stated that $94 \%$ physicians used smart devices for professional communication, accessing medical data, and improved patient professional collaboration. ${ }^{[27]}$ In this study, $78.8 \%$ students claimed that the mobile devices and software applications were a positive tool in patient education and management; however, at the time of this survey, the usage was limited to help with diagnosis and prescription of drugs. Overall students were positive about the future of technology and its impact on the patient care.

Studies have shown that ICTs should be used to understand concepts, solve tasks, and enrich innovative thinking and proficiency. This can be done through web access and sharing of online information and other network resources. ${ }^{[28-30]}$ In dental education, students could use the power of the web in the palms of their hand for a variety of learning activities such as question discussion, case presentations, and patient education.

The use of mobile technology for enhancing student learning is continually being assessed and addressed with yearly upgrade in technology. Further, there is an increasingly large focus on hardware designing (size, shape, etc.), to increase the effectiveness of M-learning. ${ }^{[21,30]}$ Finally, it should be acknowledged that the adoption of technology might make little difference to student learning outcomes if teaching is not reconceptualized to promote technology-enhanced learning. ${ }^{[31]}$ In a teacher-student equation model on mobile preferences, it has been noted that while teachers focused on technical issues for delivery, the students are more fixated on the accessibility of richness of learning content. ${ }^{[32]}$ Hence, the focus should be on M-learning tool that can conform to the preferences of the both the students and teachers.

\section{Limitations and future directions}

Greenhow and Lewin pointed out that it is essential to explore the intricate landscape of digital technologies to 
understand the full potential of self-directed learning incorporating the full potential of participatory and collaborative technologies that are grounded in competencies that educator value. ${ }^{[33]}$ The mobile devices provide the pathway to be more dynamic and ubiquitous in supporting individualized and interactive learning. This also promises access to a guided mobile library, computer-aided instruction, database activity, and electronic communication with educational potential providing information based on student's perception and preferences of mobile technology and their ability to enhance their learning outcomes. ${ }^{[34,35]}$ The study does not look at actual usefulness of various mobile applications in enhancing student learning. We hope that future studies will answer the important questions of how mobile dental application could be effectively and efficiently integrated into current teaching taking into account competencies that educator's value.

\section{CONCLUSION}

Mobile technology has provided an additional mode for accessing information and improving communication among staff and students in professional education. Although the ownership of smartphones was high, their use for learning purpose was limited. However, majority of students indicated that advances in mobile technology and with their software applications could positively assist or enhance patient education and management. M-learning should hence be considered as a tool that can effectively complement current learning techniques and bridge the gap between formal and informal learning. Further, with advances in technology, universities and health professional educators should be prepared to constantly upgrade and be prepared to provide learning experience that adapts well with the learner.

\section{Financial support and sponsorship} Nil.

\section{Conflicts of interest}

There are no conflicts of interest.

\section{REFERENCES}

1. Fabry D, Higgs J. Barriers to the effective use of technology in education: Current status. J Educ Comput Res 1997;17:385-95.

2. Yip HK, Barnes I. Learning in dental education. Eur J Dent Educ 1997;1:54-60.

3. Gikas J, Grant MM. Mobile computing devices in higher education: Student perspectives on learning with cellphones, smartphones and; social media. Internet High Educ 2013;19:18-26.

4. Liaw SS, Huang HM. Investigating acceptance toward mobile learning to assist individual knowledge management: Based on activity theory approach. Comput Educ 2010;54:446-54.

5. Kirkwood A, Price L. Technology-enhanced learning and teaching in higher education: What is "enhanced" and how do we know? A critical literature review. Learn Media Technol 2013;39:6-36.
6. Chu HC, Hwang GJ, Tsai CC, Tseng CR. A two-tier test approach to developing location-aware mobile learning systems for natural science courses. Comput Educ 2010;55:1618-27.

7. Mishra P, Koehler JM. Technological pedagogical content knowledge: A framework for teacher knowledge. Teach Coll Rec 2006;108:1017-54.

8. Motorola. How Wireless Networks are Transforming E-learning. Over View: The Increasing Use of Wireless Networks in K-12 Higher Education environment. Motorola Wireless Network Barometer Study. 2010. Available from: http://www.motorolasolutions.com/ content/dam/msi/docs/business/_documents/white_paper/_ static_files/wp_educationbarom_final.pdf. [Last accessed on 2016 Nov 21].

9. Niess ML. Preparing teachers to teach science and mathematics with technology: Developing a technology pedagogical content knowledge. Teach Teach Educ 2005;21:509-23.

10. Chen B, deNoyelles A. Exploring students' mobile learning practices in higher education. In: EDUCASE Review. 2013. Accessed from: http://er.educause.edu/articles/2013/10/exploring-students-mobilelearning-practices-in-higher-education. [Last accessed on 2016 Nov 22].

11. Ruiz JG, Mintzer MJ, Leipzig RM. The impact of E-learning in medical education. Acad Med 2006;81:207-12.

12. Venkatesh V, Morris GM, Davis BG, Davis DF. User acceptance of information technology: Toward a unified view. MIS Q 2003;27:425-78.

13. Wang YS, Wu MC, Wang HY. Investigating the determinants and age and gender differences in the acceptance of mobile learning. $\mathrm{Br}$ J Educ Technol 2009;40:92-118.

14. Ally M. Mobile learning: From research to practice to impact education. Learning and Teaching in Higher Education: Gulf Perspectives. Vol. 10. 2013. Available from: http://lthe.zu.ac.ae/index.php/ 1thehome/article/view/140. [Last accessed on 2016 Nov 22].

15. Abu-Al-Aish A, Love S. Factors influencing students' acceptance of m-learning: An investigation in higher education. Int Rev Res Open Distrib Learn 2013;14. Available from: http:/ /www.irrodl.org/index. $\mathrm{php} / \mathrm{irrodl} /$ article/view/1631. [Last accessed on 2016 Nov 21].

16. Gordon N. Flexible Pedagogies: Technology-enhanced learning. HEA 2014. Accessed from: https://www.heacademy.ac.uk/system/files/ resources/tel_report_0.pdf. [Last accessed on 2016 Nov 21].

17. Martin F, Ertzberger J. Here and now mobile learning: An experimental study on the use of mobile technology. Comput Educ 2013;68:76-85

18. Alexander, "M-Learning: Emergent Pedagogical and Campus Issues in the Mobile Learning Environment," EDUCAUSE Center for Applied Research Bulletin, vol. 2004, no. 16 (August 2004), a publication of ECAR (http://www.educause.edu/ecar/).

19. Johnson CE, Hurtubise LC, Castrop J, French G, Groner J, Ladinsky $\mathrm{M}$, et al. Learning management systems: Technology to measure the medical knowledge competency of the ACGME. Med Educ 2004;38:599-608.

20. Phelps C, Michea YF. Learning management systems' evaluation focuses on technology not learning. AMIA Annu Symp Proc 2003;2003:969.

21. Heath B, Herman R, Lugo G, Reeves J, Vetter R, Ward CR. Developing a mobile learning environment to support virtual education communities. T H E J 2005;32:33-7.

22. Oakley M, Spallek H. Social media in dental education: A call for research and action. J Dent Educ 2012;76:279-87.

23. Ponce BA, Determann JR, Boohaker HA, Sheppard E, McGwin G Jr., Theiss S. Social networking profiles and professionalism issues in residency applicants: An original study-cohort study. J Surg Educ 2013;70:502-7.

24. Maloney S, Moss A, Ilic D. Social media in health professional education: A student perspective on user levels and prospective applications. Adv Health Sci Educ Theory Pract 2014;19:687-97. 
25. Divaris K, Barlow PJ, Chendea SA, Cheong WS, Dounis A, Dragan IF, et al. The academic environment: The students' perspective. Eur J Dent Educ 2008;12 Suppl 1:120-30.

26. Bates DW, Kuperman GJ, Wang S, Gandhi T, Kittler A, Volk L, et al. Ten commandments for effective clinical decision support: Making the practice of evidence-based medicine a reality. JAMIA 2003;10:523-30.

27. Malkary G. Healthcare without Bounds: Point of Care Communications for Physicians. Menlo Park, CA: Spyglass Consulting Group; 2014.

28. Jakob N, P Kara. Eyetracking Web Usability, Society for Technical Communication: FAIRFAX; 2010. p. 428-9.

29. Williams P, Rowlands I. The Literature on Young People and their Information Behaviour, in Information Behaviour of the Researcher of the Future, A British Library/JISC Study; 2008.

30. Yılmaz Ö, Sanalan VA. M-learning: M-learning applications, students input for M-learning in science instruction. World J Educ $2011 ; 1: 172$.
31. Kirkwood A, Price L. Missing: Evidence of a scholarly approach to teaching and learning with technology in higher education. Teach High Educ 2013;18:327-37.

32. Lai C, Hwang G, Liang J, Liang JC, Tsai CC. Differences between mobile learning environmental preferences of high school teachers and students in Taiwan: A structural equation model analysis. Educ Technol Res Dev 2016;64:533-54.

33. Greenhow C, Lewin C. Social media and education: Reconceptualizing the boundaries of formal and informal learning. Learn Media Technol 2016;41:6-30.

34. Merchant G. Mobile practices in everyday life: Popular digital technologies and schooling revisited. Br J Educ Technol 2012;43:770-82.

35. Park Y. A pedagogical framework for mobile learning: Categorizing educational applications of mobile technologies into four types. Int Rev Res Open Distrib Learn 2011;12:25.

\section{New features on the journal's website}

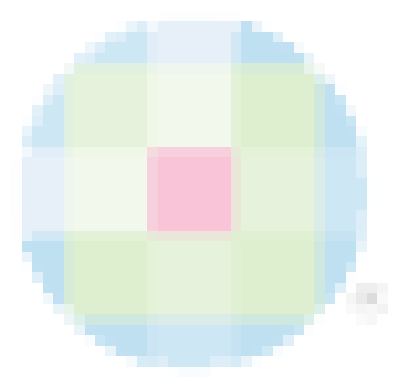

\section{Optimized content for mobile and hand-held devices}

HTML pages have been optimized of mobile and other hand-held devices (such as iPad, Kindle, iPod) for faster browsing speed.

Click on [Mobile Full text] from Table of Contents page.

This is simple HTML version for faster download on mobiles (if viewed on desktop, it will be automatically redirected to full HTML version)

\section{E-Pub for hand-held devices}

EPUB is an open e-book standard recommended by The International Digital Publishing Forum which is designed for reflowable content i.e. the text display can be optimized for a particular display device.

Click on [EPub] from Table of Contents page.

There are various e-Pub readers such as for Windows: Digital Editions, OS X: Calibre/Bookworm, iPhone/iPod Touch/iPad: Stanza, and Linux: Calibre/Bookworm.

\section{E-Book for desktop}

One can also see the entire issue as printed here in a 'flip book' version on desktops. Links are available from Current Issue as well as Archives pages.

Click on View as eBook 